\title{
Bordetella Adenylate Cyclase Toxin Can Bind Ganglioside GM1
}

\author{
Lucyna Mrówczyńska $^{{ }^{*}}$, Małgorzata Bobrowska-Hägerstrand ${ }^{2}$, Christer Lindqvist $^{2}$, Henry Hägerstrand $^{2}$ \\ ${ }^{1}$ Department of Cell Biology, A. Mickiewicz University, PL-61614, Poznań, Poland \\ 2 Department of Biosciences, Cell Biology, Åbo Akademi University, FIN-20520 Åbo-Turku, Finland
}

Lucyna Mrówczyńska; +48-61-8295824, lumro@amu.edu.pl; Małgorzata Bobrowska-Hägerstrand; +358-2154065, mhagerst@abo.fi; Christer Lindqvist; +358-2-2154053, clindqvi@abo.fi; Henry Hägerstrand; +358-2-2154748, hhagerst@abo.fi

*Correspondence to : Lucyna Mrówczyńska, PhD, Department of Cell Biology, A. Mickiewicz University, PL-61614 Poznań, Poland. Fax: +48 61829 5636.Tel: +48 61829 5824. Email address: lumro@amu.edu.pl

doi:10.5618/bio.2011.v1.n1.4 || Received: 13-04-2011, Accepted: 4-07-2011, Available online: 4-08-2011

\begin{abstract}
Adenylate cyclase toxin (CyaA) is produced by Bordetella pertussis, the causative agent of whooping cough. CyaA specifically binds to the heavily $\mathrm{N}$ glycosylated $\beta_{2}$ integrin receptor CD11b/CD18 on its main cellular target myeloid phagocytic cells. However, CyaA can also interact with and intercalate into cell membranes lacking CD11b/CD18, where saccharides may play a propagating role in membrane binding. The present study was undertaken to examine whether CyaA can bind to ganglioside GM1 (GM1), a membrane raft associated oligosaccharidebearing lipid. For this sake, the potency of highly selective GM1 ligand cholera toxin subunit B (CTB) to block CyaA binding in GM1-positive CD11b/ CD18-negative human erythrocytes and $\mathrm{K562}$ cells was studied by flow cytometry. Pre-treatment of erythrocytes and $\mathrm{K562}$ cells with CTB markedly (29\% and $28 \%$, respectively) decreased their binding of CyaA, indicating that CyaA can bind to GM1, apparently by recognizing terminal galactose and sialic acid residues in GM1.
\end{abstract}

Keywords: Bordetella pertussis; CyaA; Ganglioside GM1; Oligosaccharide; Erythrocyte; K562

\section{Introduction}

Animal cells are covered with glycoproteins and glycolipids, with their saccharide chains mainly functioning as recognition molecules. They can serve as receptors for binding other cells, proteins, bacteria, toxins and viruses [1-6]. Among the glycolipids, glycosphingolipids are the most abundant molecules here. Their sugar chains have a widely varying composition and are attached to ceramide. Sialylated glycosphingolipids are referred to as gangliosides, with ganglioside GM1 (GM1) being a member of this family. GM1 is regarded a major constituent of membrane rafts [7-8], i.e. sterolsphingolipid-enriched domains that compartmentalize cellular processes [9].

Adenylate cyclase toxin (CyaA) is a major virulence factor produced by Bordetella pertussis, the causative agent of whooping cough [10-13]. CyaA is a single palmitoylated polypeptide consisting of an aminoterminal adenylate cyclase (AC) domain and a hydrophobic hemolysin (Hly) moiety. Hly moieties entering the plasma membrane may upon oligomerisation form cation-selective channels and induce cell lysis. When the AC domain, subsequently to Hly, enters the target cell it is activated by calmodulin to catalyze ATP to cAMP, thereby inactivating target cell phagocytic functions [14].

The initial binding of CyaA to the plasma membrane surface is influenced by saccharides. Namely, CyaA can specifically bind to the heavily $\mathrm{N}$-glycosylated beta2 integrin receptor CD11b/CD18 on myeloid phagocytic cells $[15,16]$. In these cells the calcium ionophoreactivity of CyaA may trigger accumulation of the CyaAintegrin complex into membrane rafts, where translocation of the AC domain across the membrane occurs [17]. CD11b/CD18 is exclusively restricted to leukocytes $[18,19]$. However, CyaA can also interact with and intercalate into cell membranes lacking CD11b/ 
CD18, such as mammalian erythrocytes [20-26] and epithelial cells [27], where saccharides may play a propagating role in membrane binding. While the physiological significance of non-CD11b/CD18 binding of CyaA in CD11b/CD18 negative and positive cells remains unclear, gangliosides have previously been indicated as possible CyaA receptors [11].

The present study was undertaken to examine whether ganglioside GM1, a raft associated oligosaccharide-bearing lipid, can bind CyaA. If so, CyaA should compete for GM1 binding with cholera toxin subunit B (CTB), a highly specific GM1 ligand [28]. For this sake, the potency of CTB to block CyaA binding was examined in GM1-positive CD11b/CD18-negative $[18,19,29]$ human erythrocytes and K562 cells.

\section{Materials and Methods}

\subsection{Chemicals}

AlexaFluor488 conjugated wild-type CyaA toxin (CyaA-WT) [17] was a kind gift from Dr. Peter Sebo (Institute of Microbiology AS CR v.v.i., Prague, Czech Republic). CTB (C9972) was from Sigma-Aldrich, Dgalactose (4058) from Merck, D-lactose (0156) from Difco and D-mannose (63580) from Fluka.

\subsection{Cells}

Blood was drawn from the authors and volunteers by venipuncture into heparinised tubes. Blood was centrifuged to remove serum and buffy coat and erythrocytes subsecuently washed three times with buffer $\left(145 \mathrm{mM} \mathrm{NaCl}, 5 \mathrm{mM} \mathrm{KCl}, 4 \mathrm{mM} \mathrm{Na}_{2} \mathrm{HPO}_{4}, 1\right.$ $\mathrm{mM} \mathrm{NaH} \mathrm{PO}_{4}, 1 \mathrm{mM} \mathrm{MgSO}, 1 \mathrm{mM} \mathrm{CaCl}, 10 \mathrm{mM}$ glucose, $\mathrm{pH}$ 7.4). Erythrocytes were suspended in the buffer at $1.65 \times 10^{9}$ cells $/ \mathrm{ml}$, stored at $4^{\circ} \mathrm{C}$ and used within $5 \mathrm{~h}$. Erythroleukemia K562 cells, cultured as previously described [30], were pelleted and suspended in the buffer at $10 \times 10^{6}$ cells $/ \mathrm{ml}$, and immediately used.

\subsection{CyaA treatment}

Erythrocytes $\left(1.65 \times 10^{8}\right.$ cells $/ \mathrm{ml}, \sim 1.5 \%$ haematocrit $)$ or K562 cells $\left(2 \times 10^{6}\right.$ cells $\left./ \mathrm{ml}\right)$ were incubated with CyaAWT (25 $\mu \mathrm{g} / \mathrm{ml}$ according to [25]) in buffer containing 2 $\mathrm{mM} \mathrm{CaCl}_{2}$ for $30 \mathrm{~min}$ at $4^{\circ} \mathrm{C}$ and subsequently washed three times with buffer. When indicated, cells pretreated with CTB $(4 \mu \mathrm{g} / \mathrm{ml})$ for $60 \mathrm{~min}$ at RT [31] were used. To examine the effect of free saccharides on binding of CyaA-WT to the cell membrane, CyaA-WT $(25 \mu \mathrm{g} / \mathrm{ml})$ was pre-incubated with each saccharide (10 $\mathrm{mM})$ for $15 \mathrm{~min}$ at $4^{\circ} \mathrm{C}$ and then erythrocytes $\left(1.65 \times 10^{8}\right.$ cells $/ \mathrm{ml}, \sim 1.5 \%$ haematocrit) were added and incubated for the next $30 \mathrm{~min}$ at $4^{\circ} \mathrm{C}$. FACSCalibur ${ }^{\mathrm{TM}}$ flow cytometer (Becton-Dickinson Immunocytometry Sys- tems, San Jose, CA, USA) was used for measuring the cell membrane binding of CyaA-WT (excitation wavelength $488 \mathrm{~nm}$, emission channel FL1). Appropriate gating was used to exclude white blood cells. Toxins binding data were calculated from the mean fluorescence intensity (MFI) and expressed as percentage of toxin binding to untreated cells as previously described [16].

\subsection{Scanning electron microscopy}

Erythrocytes were processed for scanning electron microscopy (SEM, Leo 1530 Gemini) according to standard protocol as previously described [32].

\section{Results and Discussion}

Pre-treatment of human erythrocytes and K562 cells with CTB diminished subsequent CyaA-WT binding to cells by $29 \pm 18 \%$ and $28 \pm 13 \%$, respectively (Fig. 1). Preincubation with saccharides $(10 \mathrm{mM})$ : monosaccharide D-galactose, disaccharide D-lactose (glucose +galactose) and monosaccharide D-mannose, diminished CyaA-WT binding to human erythrocytes with 49 $\pm 18 \%, 43 \pm 19 \%$ and $39 \pm 18 \%$, respectively (Fig. 2). Sialic acid $(1 \mathrm{mM})$ showed similar inhibitor potency as D-galactose, but induced also weak haemolysis which therefore disqualified the results.

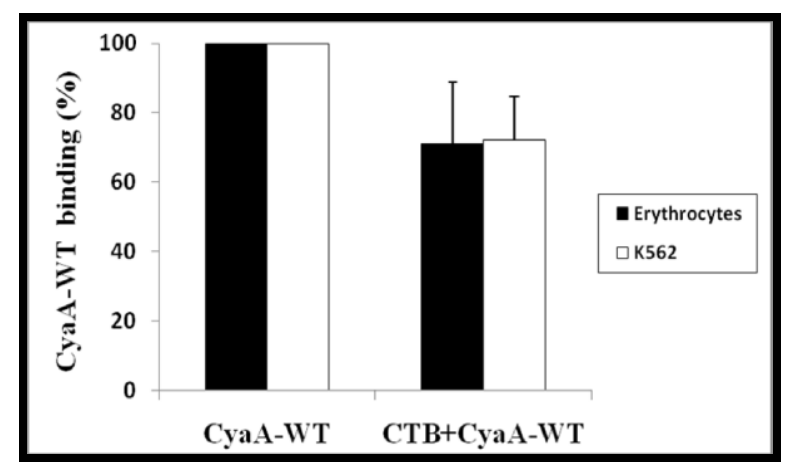

Fig. 1. Effect of pre-treatment with CTB on CyaA-WT binding to human erythrocytes and K562 cells. Pretreatment with CTB, followed by washing, diminished subsequent CyaA-WT binding in human erythrocytes and K562 cells, respectively ( $\mathrm{p}<0.01$, Student's t-test). Binding was monitored by flow cytometry, and binding data were calculated from the mean fluorescence intensity (MFI) and expressed as percentage of toxin binding to untreated cells as previously described [16]. The presented results represent the average of values obtained in four independent experiments \pm standard deviation. 


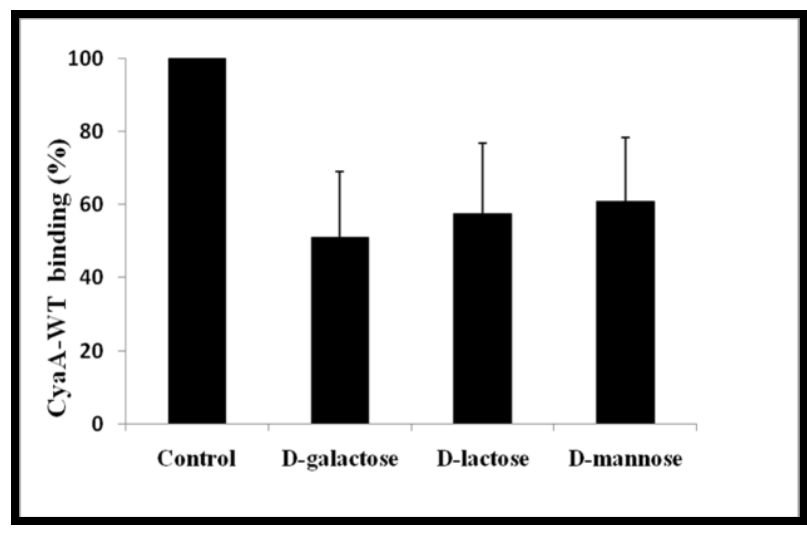

Fig. 2. Effect of free saccharides D-galactose, D-lactose, D-mannose on CyaA-WT binding to human erythrocytes. Pre-incubation with saccharides diminished CyaA-WT binding to human erythrocytes $(p<0.01$, Student's t-test). Binding was monitored by flow cytometry, and binding data were calculated from the mean fluorescence intensity (MFI) and expressed as percenttage of toxin binding to untreated cells as previously described [16]. The presented results represent the average of values obtained in four independent experiments \pm standard deviation.

CyaA-WT induced echinocytic shape alterations in human erythrocytes, similar to that induced by increased intracellular calcium [31], indicating CD11b/CD18independent CyaA-WT membrane binding and perturbation (Fig. 3).

The present study shows that CyaA can bind to ganglioside GM1, a membrane raft associated oligosaccharide-bearing lipid [7-9], in CD11b/CD18 lacking human erythrocytes and K562 cells. Gangliosides have previously been suggested as potential CyaA membrane receptors. Namely, premixing of CyaA with gangliosides inhibited CyaA-induced intoxication in Chinese hamster ovary cells [11]. While the fact that CyaA does not necessarily require a protein receptor for membrane binding may indicate that it has a broad range of host cell types [24, 26, 27, 33], the physiological significance of non-CD11b/CD18 binding of CyaA remains unclear. It seems reasonable to suggest that bacterial toxins like CyaA binds to GM1, both in its main target and other cells, in order to affect raft-associated signal-transduction processes aiding bacterial pathogenesis. GM1containing rafts could also function as shuttle platforms where toxins are translocated into cells. Lateral accumulation of oligomerised GM1-CyaA (or integrin-CyaA) complexes (rafts) may induce membrane invagination and endocytic uptake of CyaA.

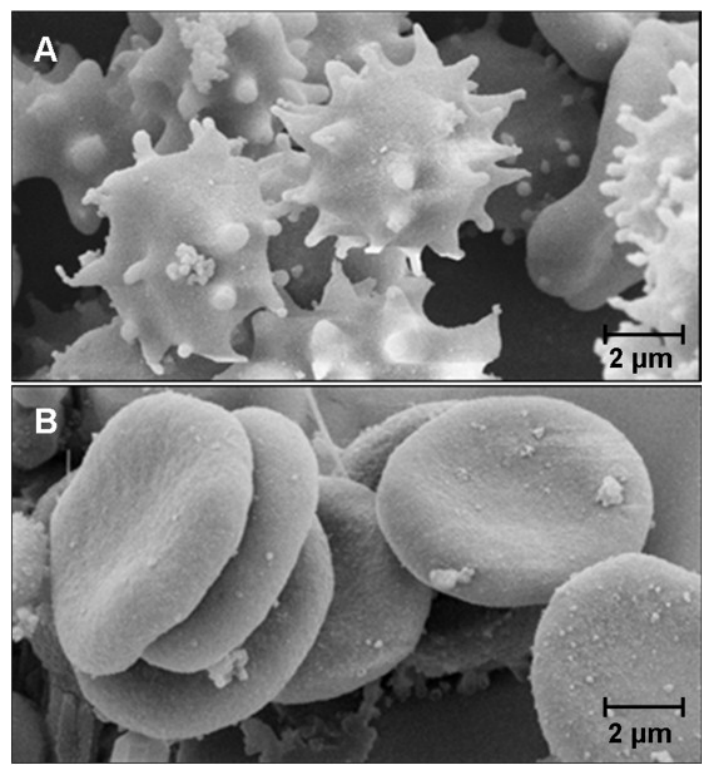

Fig. 3. CyaA-WT induced echinocytosis. Scanning electron micrograph showing that CyaA-WT induces echinocytic shape alterations in human erythrocytes (A); control (B).

The reason for the binding of CyaA to GM1 can be explained by comparing the saccharides moieties of GM1 (Fig. 4A) and CD11b/CD18 (Fig. 4B), the assumed natural receptor of CyaA. Such a comparison reveals striking similarities between the terminal parts of oligosaccharide chain of $\beta_{2}$ integrin (see [16]) and GM1 oligosaccharide chain. Namely, both of them have a terminal galactose residue, following an amine, and a

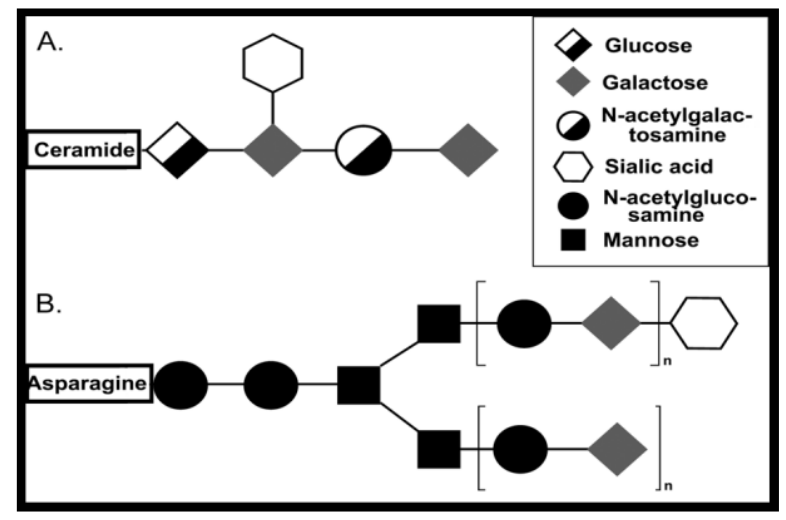

Fig. 4. Schematic chemical structure of (A) GM1 and (B) integrin receptor representative (see [16] for details).

sialic acid residue. One can therefore assume that this molecular configuration is mainly responsible for CyaA binding to GM1. Notably, CTB, used to assess CyaA binding to GM1 in the present study, binds its natural 
receptor GM1 with high selectivity, the binding depending for $54 \%$ on the terminal galactose moiety and for $44 \%$ on the sialic acid moiety [28]. In addition, CyaA may also bind to other sugar chains, as indicated by the potency of D-mannose to diminish membrane binding of CyaA (Fig. 3). Furthermore, CyaA may also to some degree intercalate into biological membranes without the aid of receptors, since it binds to liposomes [24]. Interestingly, CyaA was recently shown to intoxicate CD11b/CD18 lacking epithelial cells without the evident aid of any specific membrane receptor [27].

\section{Conclusion}

CyaA specifically binds to the heavily N-glycosylated beta2 integrin receptor $\mathrm{CD} 11 \mathrm{~b} / \mathrm{CD} 18$ on myeloid phagocytic cells. CD11b/CD18 is exclusively restricted to leukocytes. However, CyaA can also bind to a variety of other cell types lacking CD11b/CD18 receptors, such as mammalian erythrocytes where the binding mechanism is poorly understood. In this study, the binding of CyaA to GM1 in human erythrocytes and K562 cells could be demonstrated and given a plausible explanation. Notably, CyaA may simultaneously bind to other sugar chains besides those of GM1. Besides that the fluorescence/binding of Alexa 488 conjugated CyaA is sensitive to post-fixation (results not shown), studies with CyaA are complicated by the short distance activity of CyaA due to rapid inactivation and aggregation in solution following secretion or refolding from urea stocks $[14,26]$.

\section{Acknowledgements}

Gunilla Henriksson, Esa Nummelin, Thomas Bymark, and Jari Korhonen are gratefully acknowledged for their technical assistance.

\section{References}

[1] Karlsson, K. A. Animal glycosphingolipids as membrane attachment sites for bacteria. Annu. Rev. Biochem. 1989, 58, 309-350. doi:10.1146/annurev.bi.58.070189.001521

[2] Varki, A. Biological roles of oligosaccharides: all of the theories are correct. Glycobiology 1993, 3, 97130. doi: 10.1093/glycob/3.2.97

[3] Yates, A. J.; Rampersaud, A. Sphingolipids as receptor modulators. An overview. Ann. NY Acad. Sci. 1998, 845, 57-71. doi:10.1111/j.1749-6632.1998.tb09662.x
[4] Lowe, J. B.; Marth, J. D. A genetic approach to Mammalian glycan function. Annu. Rev. Biochem. 2003, 72, 643-691. doi:10.1146/annurev.biochem.72.121801.161809

[5] Taylor, M. E.; Drickamer, K. Introduction to Glycobiology, Oxford University Press, Oxford, UK; 2003. p207.

[6] Larsson, E. A.; Olsson, U.; Whitmore, C. D.; Martins, R.; Tettamanti, G.; Schnaar, R. L.; Dovichi, N. J.; Palcic, M. M.; Hindsgaul, O. Synthesis of reference standards to enable single cell metabolomic studies of tetramethylrhodamine-labeled ganglioside GM1. Carbohydr. Res. 2007, 342, 482489. doi:10.1016/j.carres.2006.10.002

[7] Harder, T.; Scheiffele, P.; Verkade, P.; Simons, K. Lipid domain structure of the plasma membrane revealed by patching of membrane components. $J$. Cell Biol. 1998, 141, 929-942.

doi:10.1083/jcb.141.4.929

[8] Janes, P. W.; Ley, S. C.; Magee, A. I. Aggregation of lipid rafts accompanies signaling via the $\mathrm{T}$ cell antigen receptor. J. Cell Biol. 1999, 147, 447-461. doi:10.1083/jcb.147.2.447

[9] Pike, L. J. Rafts defined: a report on the Keystone Symposium on Lipid Rafts and Cell Function. $J$. Lipid Res. 2006, 47, 1597-1598. doi:10.1194/jlr.E600002-JLR200

[10] Hanski, E.; Farfel, Z. Bordetella pertussis invasive adenylate cyclase. Partial resolution and properties of its cellular penetration. J. Biol. Chem. 1985, 260, 5526-5532. PMid:2859287

[11] Gordon, V. M.; Young, Jr, W. W.; Lechler, S. M.; Gray, M. C.; Leppla, S. H.; Hewlett, E. L. Adenylate cyclase toxins from Bacillus anthracis and Bordetella pertussis. Different processes for interaction with and entry into target cells. J. Biol. Chem. 1989, 264, 14792-14796. PMid:2504710

[12] Hackett, M.; Guo, L.; Shabanowitz, J.; Hunt, D. F.; Hewlett, E. L. Internal lysine palmitoylation in adenylate cyclase toxin from Bordetella pertussis. Science 1994, 266, 433-435. doi:10.1126/science.7939682

[13] Ladant, D.; Ullmann, A. Bordatella pertussis adenylate cyclase: a toxin with multiple talents. Trends Microbiol. 1999, 7, 172-176. doi:10.1016/S0966-842X(99)01468-7

[14] Vojtova, J.; Kamanova, J.; Sebo, P. Bordetella adenylate cyclase toxin: a swift saboteur of host defense. Curr. Opin. Microbiol. 2006, 9, 69-75. doi:10.1016/j.mib.2005.12.011 
[15] Guermonprez, P.; Khelef, N.; Blouin, E.; Rieu, P.; Ricciardi-Castagnoli, P.; Guiso, N.; Ladant, D.; Leclerc, C. The adenylate cyclase toxin of Bordetella pertussis binds to target cells via the alpha(M)beta(2) integrin (CD11b/CD18). J. Exp. Med. 2001, 193, 1035-1044. doi:10.1084/jem.193.9.1035

[16] Morova, J.; Osicka, R.; Masin, J; Sebo, P. RTX cytotoxins recognize beta2 integrin receptors through N-linked oligosaccharides. Proc. Natl. Acad. Sci. USA 2008, 105, 5355-5360. doi:10.1073/pnas.0711400105

[17] Bumba, L.; Masin, J.; Fiser, R.; Sebo, P. Bordetella adenylate cyclase toxin mobilizes its beta2 integrin receptor into lipid rafts to accomplish translocation across target cell membrane in two steps. PLoS Pathog. 2010, 6, e1000901. doi:10.1371/journal.ppat.1000901

[18] Arnaout, M. A. Structure and function of the leukocyte adhesion molecules CD11/CD18. Blood, 1990, 75, 1037-1050. PMid:1968349

[19] Mazzone, A.; Ricevuti, G. Leukocyte CD11/CD18 integrins: biological and clinical relevance. Haematologica 1995, 80, 161-175. PMid:7628754

[20] Ehrmann, I. E.; Gray, M. C.; Gordon, V. M.; Gray, L. S.; Hewlett, E.L. Hemolytic activity of adenylate cyclase toxin from Bordetella pertussis. FEBS Lett. 1991, 278, 79-83. doi:10.1016/0014-5793(91)80088$\underline{K}$

[21] Rogel, A.; Meller, R.; Hanski, E. Adenylate cyclase toxin from Bordetella pertussis. The relationship between induction of cAMP and hemolysis. J. Biol. Chem.1991, 266, 3154-3161. PMid:1847141

[22] Gray, M.C.; Ross, W.; Kim, K.; Hewlett, E. L. Characterization of binding of adenylate cyclase toxin to target cells by flow cytometry. Infect. Immun. 1999, 67, 4393-4399. PMid:10456879

[23] El-Azami-El-Idrissi, M.; Bauche, C.; Loucka, J.; Osicka, R.; Sebo, P.; Ladant, D.; Leclerc, C. Interaction of Bordetella pertussis adenylate cyclase with CD11b/CD18: Role of toxin acylation and identification of the main integrin interaction domain. J. Biol. Chem. 2003, 278, 38514-38521. doi:10.1074/jbc.M304387200

[24] Martín, C.; Requero, M. A.; Masin, J.; Konopasek, I.; Goñi, F. M.; Sebo, P.; Ostolaza, H. Membrane restructuring by Bordetella pertussis adenylate cyclase toxin, a member of the RTX toxin family. $J$. Bacteriol. 2004, 186, 3760-3765. doi:10.1128/JB.186.12.3760-3765.2004
[25] Vojtová, J.; Kofronová, O.; Sebo, O.; Benada, O. Bordetella adenylate cyclase toxin induces a cascade of morphological changes of sheep erythrocytes and localizes into clusters in erythrocyte membranes. Microsc. Res. Tech. 2006, 69, 119-129. doi:10.1002/jemt.20277

[26] Vojtova-Vodolanova, J.; Basler, M.; Osicka, R.; Knapp, O.; Maier, E.; Cerny, J.; Benada, O.; Benz, R.; Sebo, P. Oligomerization is involved in pore formation by Bordetella adenylate cyclase toxin. FASEB J. 2009, 23, 2831-2843. doi:10.1096/fj.09$\underline{131250}$

[27] Eby, J.C.; Ciesla, W. P.; Hamman, W.; Donato, G. M.; Pickles, R. J.; Hewlett, E. L.; Lencer, W. I. Selective translocation of the Bordetella pertussis adenylate cyclase toxin across the basolateral membranes of polarized epithelial cells. J. Biol. Chem. 2010, 285, 10662-10670. doi:10.1074/jbc.M109.089219

[28] Turnbull, W. B.; Precious, B. L.; Homans, S.W. Dissecting the cholera toxin-ganglioside GM1 interaction by isothermal titration calorimetry. $\mathrm{J}$. Am. Chem. Soc. 2004, 126, 1047-1054.

doi:10.1021/ja0378207

[29] Xiong, Y. M.; Chen, J.; Zhang, L. Modulation of CD11b/CD18 adhesive activity by its extracellular,membrane-proximal regions. J. Immunol. 2003, 171, 1042-1050. PMid:12847278

[30] Lozzio, C. B.; Lozzio, B. Human chronic myelogenous leukemia cell-line with positive Philadelphia chromosome. Blood 1975, 45, 321-324.

[31] Hägerstrand, H.; Mrówczyńska, L.; Salzer, U.; Prohaska, R.; Michelsen, K.; Kralj-Iglič, V.; Iglič, A. Curvature dependent lateral distribution of raft markers in the human erythrocyte membrane. Mol. Membr. Biol. 2006, 23, 277-288. doi:10.1080/09687860600682536

[32] Hägerstrand, H.; Isomaa, B. Morphological characterization of exovesicles and endovesicles released from human erythrocytes following treatment with amphiphiles. Biochim. Biophys. Acta 1992, 1109, 117-126. doi:10.1016/0005-2736(92)90074-V

[33] Welch, R. A. RTX toxin structure and function: a story of numerous anomalies and few analogies in toxin biology. Curr. Top Microbiol. Immunol. 2001, 257, 85-111. PMid:11417123 